\title{
Thermal Plasma Synthesis of Metal-Boride Nanoparticles as a Functional Material for Gamma-Ray Shielding
}

\author{
Received 3 January, 2022; revised 20 January, 2022; accepted 20 January, 2022
}

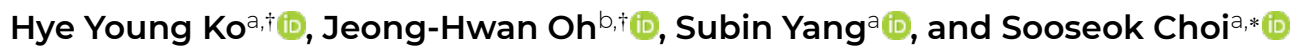 \\ aDepartment of Nuclear and Energy Engineering, Jeju National University, Jeju 63243, Republic of Korea \\ bElectric Energy Research Center, Jeju National University, Jeju 63243, Republic of Korea
}

†These authors contributed equally to this work as first author.

*Corresponding author E-mail: sooseok@jejunu.ac.kr

\begin{abstract}
We performed a synthesis of metal-boride nanoparticles, which can shield both gamma rays and neutrons, and investigated the radiation shielding performance of the material. Titanium and nickel boride nanoparticles were synthesized in a triple thermal plasma jet system using titanium (Ti), nickel (Ni), and amorphous boron (a-B). The average sizes of the titanium boride and nickel boride were 46.3 and $31.4 \mathrm{~nm}$, respectively. In the titanium boride, the $\mathrm{TiB}_{2}$ phase was the major crystal structure with $\mathrm{TiB}$ as a minor phase, and the peak of the starting materials could not be observed. On the other hand, the nickel boride indicated a major crystal structure of NiB with an Ni peak observed from $\mathrm{X}$-ray diffraction graphs. The synthesized powders were applied as a coating material to shield the radiation. The shielding performance of the coating material made with synthesized powder was analyzed using ${ }^{137} \mathrm{Cs}$ source $(662 \mathrm{keV})$. The attenuation coefficient of the nickel boride and titanium boride was 0.246 and $0.197 \mathrm{~cm}^{-1}$, respectively. Boron-rich boride is stable when confronting neutron and other types of radiation. Therefore, synthesized metal-boride nanoparticles can be used as substitutes for heavy metals, which become radioactive on account of neutron exposure.
\end{abstract}

Keywords: Thermal plasma, Metal-boride nanoparticles, Coating material, Radiation shielding

\section{Introduction}

Boron has a high melting point of 2,349 $\mathrm{K}$ and a lightweight property with a low density of $2.35 \mathrm{~g} / \mathrm{cm}^{3}[1]$. The materials containing boron, such as refractory polymers, boron fibers, metal borides, and boron carbide, are widely used in various industries [2-5]. Among these materials, metal boride has a high melting point, excellent wear resistance, and chemical inertness owing to its strong covalent metalboron bonds [6]. In particular, nickel boride can be used an efficient catalyst for selective reduction of halides and nitro compounds $[7,8]$. The metal borides have large cross-sections for neutron absorption because of the presence of the element boron, and they are highly suited for use in extreme conditions such as high-temperature or radiative environments. In addition, they can be used as a shielding material owing to their many boron-rich borides, which are stable in the face of neutron and other types of radiation [9].

Synthesizing metal boride requires high-temperature environments because boron has high melting and boiling points. It is therefore challenging to make metal-boride nanoparticles by the general synthesis method. Thus, they have been synthesized using thermal plasma, which generates a high-temperature region of $10,000 \mathrm{~K}$ [10-12]. Thermal plasma used in the synthesis of metal-boride nanoparticles is generated by various discharge sources such as direct current (DC) and radio frequency (RF) [13]. A DC thermal plasma torch can be used to easily control the discharge environment, whereas a RF plasma discharge is highly sensitive and shows relatively low stability owing to an impedance matching box. Moreover, the DC torch system has high thermal efficiency, a low operating cost, and a small system scale compared with an RF torch system [9].

In this study, two metal-boride nanoparticles were synthesized using triple DC thermal plasma. This system was introduced to produce a large plasma flame with high temperatures, and the starting materials could be injected into the merged plasma flame. Generally, a single DC torch has difficulty injecting the starting materials into the high temperature region because of the high flow velocity and the viscosity of the plasma $[14,15]$. The metal boride was synthesized in the present study from titanium, nickel, and boron as the starting materials. The synthesized powders were used as a coating material for shielding radiation, and their shielding performance was analyzed for the ${ }^{137} \mathrm{Cs}$ gamma ray.

\section{Experimental}

\subsection{Synthesis of nanoparticles}

Figure 1 presents photographs of the triple DC thermal plasma system that was used to synthesize the metal-boride nanoparticles. The system consists of three DC torches, a reactor, a filter, power supplies, mass flow controllers (MFCs), and cooling-water flow meters, as indicated in Fig. 1(a). The reactor with cooling water is divided into seven parts and cools the high-temperature fluid generated from the triple plasma jets. Then, the injected gas is vented after passing through the 


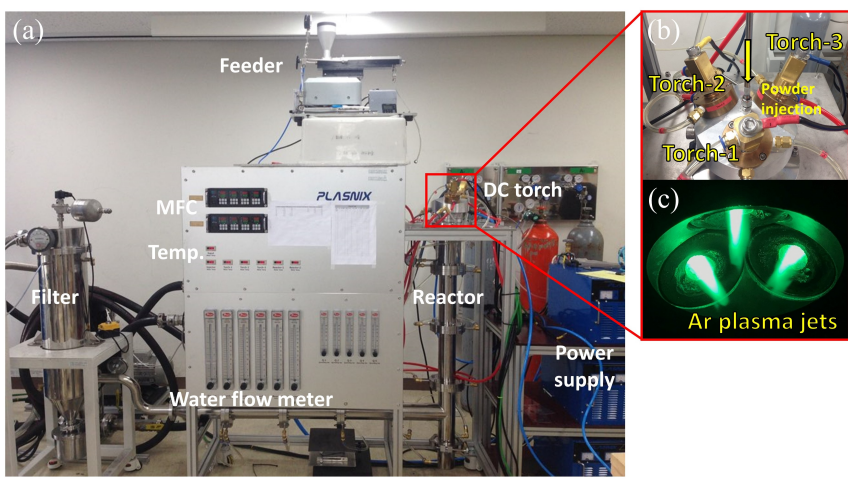

Figure 1. Photographs of triple DC thermal plasma system for the synthesis of metal boride nanoparticles: (a) Triple DC thermal plasma system, (b) configuration of the triple torch with injector, and (c) triple argon plasma jets.

filter. The vertical and horizontal axis are 120 and $140 \mathrm{~cm}$, respectively. The configuration of the DC torch system is designed so that the plasma jets merge at the center of the reactor. The starting materials are injected between torches with the carrier gas, as shown in Figs. 1(b) and 1(c). This photograph depicts the Ar plasma jets with low input power and the low flow rate of the plasma-forming gas.

The experimental conditions are summarized in Table I. We carried out the synthesis experiment of the metal-boride nanoparticles under the total input power of $28 \mathrm{~kW}$ and atmospheric pressure. The plasmaforming gas was supplied as mixed gas with Ar $28 \mathrm{~L} / \mathrm{min}$ and $\mathrm{N}_{2} 14$ $\mathrm{L} / \mathrm{min}$. The precursor used was micro-sized titanium $(<30 \mu \mathrm{m}$, Yeeyoung CeraChem Ltd., Republic of Korea), nickel $(<10 \mu \mathrm{m}$, Yeeyoung CeraChem Ltd., Republic of Korea), and nano-sized boron powder (<80 nm, Yeeyoung CeraChem Ltd., Republic of Korea). The starting materials were prepared by mixing each metal $(\mathrm{Ti}$ and $\mathrm{Ni})$ with the boron powder. They were then injected at a fixed feed rate of 1 $\mathrm{g} / \mathrm{min}$ with $\operatorname{Ar} 5 \mathrm{~L} / \mathrm{min}$. The characteristics of the synthesized powder were investigated by X-ray diffraction (XRD, D2 Phaser, Bruker Corp., USA) with $\mathrm{CuK}_{\alpha}$ radiation $(\lambda=1.5406 \AA)$, a field emission scanning electron microscope (FE-SEM, S-4800, HITACHI, Japan) with $15 \mathrm{kV}$ accelerating voltage, and a field emission transmission electron microscope (FE-TEM, JEM-2100F, JEOL Ltd., Japan) at $200 \mathrm{kV}$ accelerating voltage.

\subsection{Preparation of coating material}

Two types of nanoparticles were synthesized using a thermal plasma, and they were used as gamma-ray shielding materials. The shielding material manufacturing method was as follows. First, to obtain the uniform mixture of coating paste, a carboxymethyl cellulose (CMC) binder and deionized water were mixed in a mortar and pestle for 30 min. The mass ratios between the metal boride and the binder were 2:1 for nickel boride and 4:1 for titanium boride. Second, the paste form of the shielding material was coated at a homogeneous thickness using a doctor blade. It was then left to dry in air for at least $18 \mathrm{~h}$. Nickel boride and titanium boride of $0.3,0.2$, and $0.1 \mathrm{~mm}$ thicknesses were manufactured to evaluate the radiation shielding performance.

\subsection{Radiation shielding performance}

Figure 2(a) presents the measurement system of radiation shielding, which consists of the radiation source, collimator, and shielding material. To calculate the attenuation coefficient of the shielding materials, a gamma-ray shielding test system was constructed using a Geiger-Mueller (GM) counter and collimator, as shown in Fig. 2(b). The collimator was made of lead to completely absorb the dose of photons and to focus the radiation accordingly to the area of interest. The operating conditions of the GM counter were $560 \mathrm{~V}$ at $600 \mathrm{~s}$, and the (a)
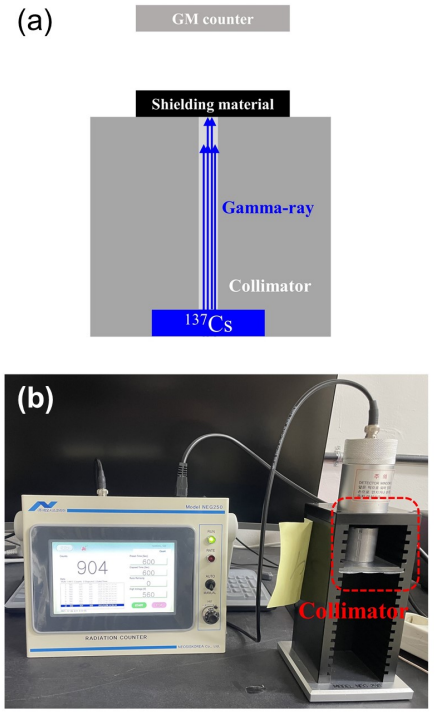

Figure 2. Configuration of radiation shielding experiment: (a) Photograph of experiment equipment and (b) schematic diagram of shielding experiment.

measurement was repeated eight times to reduce the measurement error risk. The background was measured by placing the ${ }^{137} \mathrm{Cs}(662$ $\mathrm{keV}$ ) source at the bottom of the collimator. The coating materials were placed on the upper area of the collimator, and the transmission rate was then measured for each thickness of the shielding material.

\section{Results and discussion}

\subsection{Characteristics of as-synthesized nanoparticles}

Figure 3 shows XRD graphs for the synthesized powders in the triple DC thermal plasma system. The lower portion of Fig. 3 presents the XRD graph of the synthesized titanium boride. Beneath that graph is the synthesized nickel boride graph. $\mathrm{A} \mathrm{TiB}_{2}$ crystalline phase is predominantly observed, and $\mathrm{TiB}$ shows a relatively weak intensity. A peak of titanium as the starting material does not exist, and it is revealed that the injected titanium is completely vaporized by the thermal plasma flame. The $\mathrm{TiB}_{2}$ from $6,500 \mathrm{~K}$ is formed earlier than the $\mathrm{TiB}$ for which the Gibbs free energy is less than $4,800 \mathrm{~K}$ [16]. This finding underscores that the $\mathrm{TiB}_{2}$ was synthesized through a long resistance time in the high temperature region. Thus, the higher intensity $\mathrm{TiB}_{2}$ is more readily identified than $\mathrm{TiB}$ in the $\mathrm{XRD}$ graph of Fig. 3.

In the nickel boride, $\mathrm{NiB}$ has a higher peak than $\mathrm{Ni}_{2} \mathrm{~B}$ and $\mathrm{Ni}_{4} \mathrm{~B}_{3}$, and the peak of nickel as the starting material is observed at 44.5 and $51.8^{\circ}$, as indicated in the upper graph of Fig. 3 . It is shown by the XRD graphs that their crystallinity is relatively lower than that of the synthesized titanium boride. That means that nickel boride was grown in a shorter residence time in plasma flame than the titanium boride. In the Gibbs free energy, the titanium boride synthesis was relatively spontaneous compared to the nickel boride [16]. Hence, the titanium

Table I. Experimental conditions for the synthesis of metal boride nanoparticles.

\begin{tabular}{|c|c|}
\hline \multicolumn{2}{|c|}{ Experimental conditions } \\
\hline Total input power & $28 \mathrm{~kW}$ \\
\hline Chamber pressure & $101.325 \mathrm{kPa}$ \\
\hline Plasma forming gas & Ar $28 \mathrm{~L} / \mathrm{min}$ and $\mathrm{N}_{2} 14 \mathrm{~L} / \mathrm{min}$ \\
\hline Carrier gas & $\operatorname{Ar} 5 \mathrm{~L} / \mathrm{min}$ \\
\hline Feed rate & $1 \mathrm{~g} / \mathrm{min}$ \\
\hline Starting materials (molar ratio) & $\mathrm{Ti}: \mathrm{B}=1: 2, \mathrm{Ni}: \mathrm{B}=1: 1$ \\
\hline
\end{tabular}




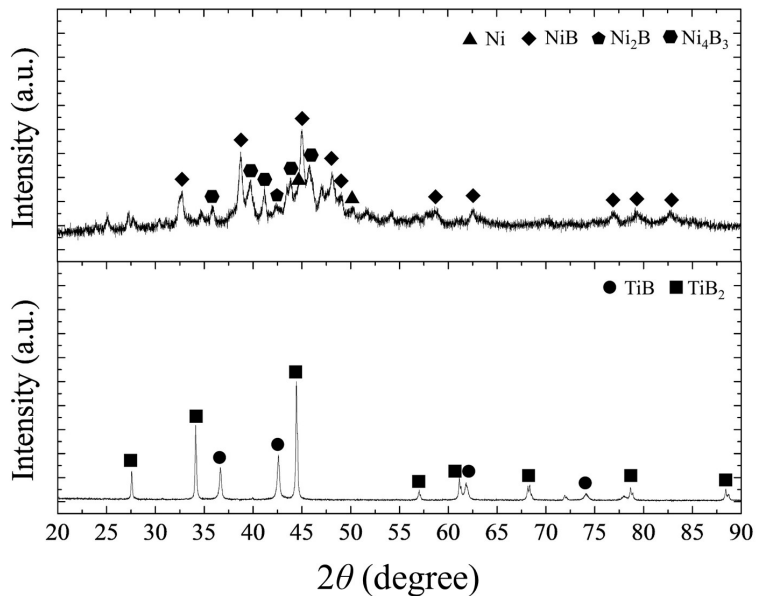

Figure 3. XRD graphs of the synthesized powders in triple DC thermal plasma system.

boride nanoparticles were synthesized through a sufficiently longer residence time than the nickel boride in the plasma flame environment.

The morphology and size of the synthesized powder were analyzed by FE-SEM and FE-TEM, as shown in Fig. 4. Figures 4(a)-(c) present those of the synthesized titanium boride, and Figs. 4(d)-(f) present those of the synthesized nickel boride. As observed in Figs. 4(c) and 4(f), the sizes of 100 particles are measured using the high-resolution FE-TEM images. The nanoparticles are spherical, and their particle sizes range from 10 to $85 \mathrm{~nm}$. The average sizes of the titanium boride and nickel boride are 46.3 and $31.4 \mathrm{~nm}$, respectively. The size distribution of the nickel boride is between 5 and $60 \mathrm{~nm}$, which is considerably narrow because the crystal growth is shorter than the titanium boride in the plasma flame. As a result, the size and crystallinity of the synthesized powder are strongly related to the nucleation temperature in accordance with the metal elements as starting materials.

\subsection{Shielding performance}

The attenuation coefficient of the shielding material with the synthesized powder was calculated based on the gamma-ray transmission rate by changing the material thickness. The attenuation coefficient of each sample was calculated by exponentially fitting the obtained transmission rate. The attenuation of gamma rays, which is caused by the
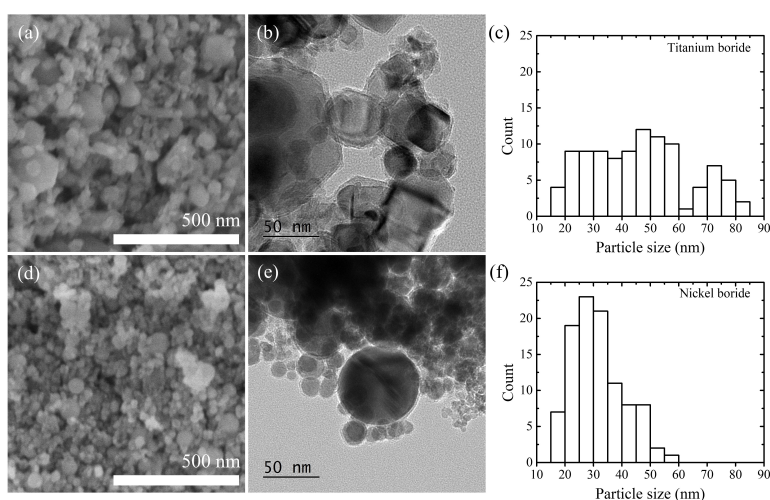

Figure 4. FE-SEM images, FE-TEM images, and particles size distribution of the synthesized powders: $(a-c)$ Titanium boride and $(d-f)$ Nickel boride.

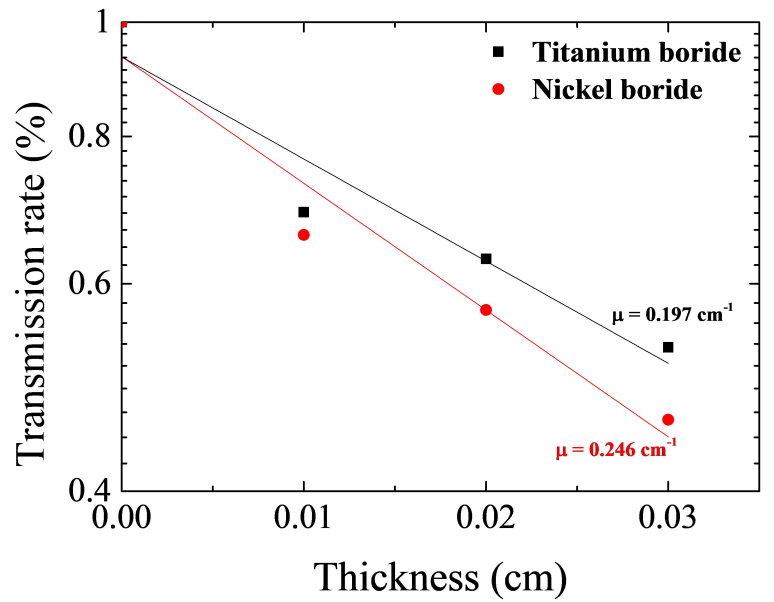

Figure 5. Transmission rates of coating material made from the synthesized powders in accordance with increasing coating thickness.

rays passing through a material, occurs exponentially, and the attenuation coefficient characterizes how easily a volume of material can be penetrated by radiation. Because the photoelectric effect, Compton scattering, and pair production-which occur independently inside the shielding material-react with the gamma rays, the attenuation coefficient denotes the sum of each process. Figure 5 shows the transmission rate in accordance with the increasing thickness and the calculated attenuation coefficient. In titanium boride, the transmission rate is reduced from 69 to $53 \%$ in accordance with the increasing thickness, whereas the transmission rate for nickel boride decreases from 66 to $46 \%$. The attenuation slope of nickel boride is larger than that of titanium boride, and the attenuation coefficient of the nickel boride and titanium boride is calculated at 0.246 and $0.197 \mathrm{~cm}^{-1}$, respectively. It is considered that the attenuation coefficient of nickel boride is high because the density of nickel is greater than that of titanium.

The linear attenuation coefficients of lead and bismuth for gamma rays $(0.662 \mathrm{MeV})$ are 1.0507 and $1.245 \mathrm{~cm}^{-1}$, respectively. Since lead and bismuth have higher attenuation coefficients than metal-boride nanomaterials, it can be said that the shielding performance of gamma rays is higher. However, lead and bismuth have disadvantages: neutron shielding is impossible, and gamma rays can pass through a pinhole and are heavy. In the case of metal-boride nanomaterials, however, the disadvantages related to pinholes and neutrons can be resolved because they are capable of simultaneously shielding neutrons and gamma rays.

\section{Conclusions}

Metal-boride nanoparticles were synthesized through a triple DC thermal plasma system, and synthesized powder was applied as a coating material for gamma-ray shielding. This coating material is applicable in areas of the nuclear industry, such as for protecting the human body and electronic devices from radiation. In a nanoparticle synthesis experiment, the synthesized titanium boride had an average size of $46.3 \mathrm{~nm}$ with a major phase structure of $\mathrm{TiB}_{2}$. In contrast, the nickel boride was $31.4 \mathrm{~nm}$ and had a major peak $\mathrm{NiB}$ with a minor peak $\mathrm{NiB}_{2}$, $\mathrm{Ni}_{2} \mathrm{~B}$, and $\mathrm{Ni}_{4} \mathrm{~B}_{3}$. The particle size of the nickel boride was smaller than that of the titanium boride because the vaporized titanium and boron had longer particle growth time than the nickel and boron.

The synthesized powders were used as a coating material for shielding radiation, and shielding performance was analyzed for the ${ }^{137} \mathrm{Cs}$ gamma ray. Their attenuation coefficient was $0.246 \mathrm{~cm}^{-1}$ for the nickel boride and $0.197 \mathrm{~cm}^{-1}$ for the titanium boride. The shielding performance of the nickel boride was confirmed to be slightly better than 
that of titanium boride on account of its relatively high density. These metal-boride nanoparticles can shield both neutrons and gamma rays and can therefore be used as a functional material in nuclear, space, and electronics industries.

\section{Acknowledgements}

This research was supported by the 2020 Scientific Promotion Program funded by Jeju National University.

\section{Conflicts of Interest}

The authors declare no conflicts of interest.

\section{ORCID}

Hye Young Ko

Jeong-Hwan $\mathrm{Oh}$

Subin Yang

Sooseok Choi

https://orcid.org/0000-0002-0503-0829 https://orcid.org/0000-0002-1426-1354 https://orcid.org/0000-0002-4174-9136 https://orcid.org/0000-0002-3957-8956
[5] S. S. Xie, L. T. Su, J. Guo, O. Vasylkiv, H. Borodianska, Z. Xi, G. M. Krishnan, H. Su, and A. I. Y. Tok, J. Nanosci. Nanotechnol. 12, 596 (2012).

[6] J. P. Scheifers, Y. Zhang, and B. P. T. Fokwa, Acc. Chem. Res. 50, 2317 (2017)

[7] R. Paul, P. Buisson, and N. Joseph, Ind. Eng. Chem. 44, 1006 (1952).

[8] L. J. E. Hofer, J. F. Shultz, R. D. Panson, and R. B. Anderson, Inorg. Chem. 3, 1783 (1964).

[9] T. H. Kim, J. H. Oh, M. Kim, S. H. Hong, and S. Choi, Appl. Sci. Converg. Tchnol. 29, 117 (2020).

[10] M. Shigeta and T. Watanabe, J. Therm. Spray Technol. 18, 1022 (2009).

[11] T. Lundstrom, Pure Appl. Chem. 57, 1383 (1985).

[12] R. G. Munro, J. Res. Natl. Inst. Stand. Technol. 105, 709 (2000).

[13] K. S. Kim and T. H. Kim, J. Appl. Phys. 125, 070901 (2019).

[14] T. H. Kim, Y. H. Lee, M. Kim, J. H. Oh, and S. Choi, IEEE Trans. Plasma Sci. 47, 3366 (2019).

[15] J. H. Oh, M. Kim, Y. H. Lee, S. H. Hong, T. H. Kim, and S. Choi, J. Nanosci. Nanotechnol. 19, 6277 (2019).

[16] M. Kim, J. H. Oh, Y. H. Lee, S. H. Hong, T. H. Kim, and S. Choi, J. Nanosci. Nanotechnol. 19, 6264 (2019).

\section{References}

[1] W. G. Woods, Environ. Health Perspect. 102, 5 (1994).

[2] H. Schuerch, AIAA J. 4, 102 (1966).

[3] T. Francois, J. Eur. Ceram. Soc. 6, 205 (1990).

[4] V. Domnich, S. Reynaud, R. A. Haber, and M. Chhowalla, J. Am. Ceram. Soc. 94, 3605 (2011). 